www.nature.com/pj

\title{
MEMORIAL PAPER
}

\section{Mixed polymerization}

\author{
Ichiro Sakurada* \\ Polymer Journal (2012) 44, 11-13; doi:10.1038/pj.2011.122
}

\begin{abstract}
Translated reproduction of Sakurada, I. Mixed Polymerization [Kongo Jugo]**. In: Polymer Chemistry Association [Kobunshi Kagaku Kyokai]*** (ed.) 'High Polymerization Reaction[Koujugo Hannno]', 35-41, 1946, Tokyo. (Selected Books on Polymers; Vol. 3) Translation by Yutaka Sakurada
\end{abstract}

Polymerization processes conducted with one kind of monomer are called 'single polymerizations' (or 'homopolymerizations'). Alternatively, polymerizations conducted with two or more kinds of monomers are called 'mixed polymerizations' (or copolymerizations). As applications of synthetic resins become broader and as materials are refined for specific targets, resins with properties intermediate to those of two or more types of synthetic resins are often required. For this reason, polymer blends sometimes become necessary. However, combining different polymers is generally difficult, and finely mixed blends with long-term stability cannot be attained. To cope with this problem, two or more types of monomers have been mixed and polymerized, and several examples of successful industrial applications have been demonstrated. Such examples include mixed polymerizations of vinyl chloride with vinyl acetate, vinyl chloride with acrylic ester, and butadiene with acrylonitrile. When mixed polymerization is performed, we can expect not only properties intermediate to those of the two separately synthesized polymers but also entirely different, copolymer-specific properties. It is still questionable whether mixed polymerizations (copolymers) will take the place of alloys of metallic materials, but their importance will certainly increase in the near future.

Published reports on the theoretical study of mixed polymerizations are relatively scarce. Although the article published by Wall on the structure of vinyl copolymers is interesting, the author regrettably assumed that polymerization is a first-order reaction and concluded that, when two kinds of monomers ( $\mathrm{X}$ and $\mathrm{Y}$ ) are mixed and polymerized, the consumption rate of $\mathrm{X}$ is proportional only to the concentration of $\mathrm{X}$ and that of $\mathrm{Y}$ is proportional only to the concentration of $\mathrm{Y}$. As a result, his theory does not contribute to an understanding of the mechanism of mixed polymerization. [Editorial note: These comments refer to Wall, F.T., J. Am. Chem. Soc., 63, 1802 (1941). In this work, Wall treated what he termed 'ideal copolymerization'. Ideal copolymerization gives 'random copolymers', that is, copolymers in which the monomer units arrangement along the chain is random or independent of adjacent units. Therefore, ideal copoly- merization can be rigorously treated without introducing, for example, the steady-state assumption. Using this assumption, Wall later reported a more general theory of copolymerization (Wall, F.T., J. Am. Chem. Soc., 66, 2050 (1944)), which is essentially the same as the one developed here by Sakurada. (Also see the Foreword.)]

By applying the polymerization mechanism previously outlined in chapters 1 and 2 to the mixed polymerization of two different types of monomers, various phases of mixed polymerization can be comprehensively understood. [Editorial note: Here only Chapter 8 'Mixed Polymerization' of the book 'High Polymerization Reactions' is translated. Hence, Chapter 1 'Mechanism of Chain Polymerization Reactions' and Chapter 2 'Kinetics of Polymerization Reactions' do not appear in this translation.] In this chapter, the proposed mechanism is discussed in detail.

In the following discussion, the two different monomers are represented as $\mathrm{X}$ and $\mathrm{Y}$, and their activated molecules are symbolized by $\mathrm{X}^{*}$ and $\mathrm{Y}^{*}$, respectively. Thus, $\mathrm{X}^{*}$ or $\mathrm{Y}^{*}$ designates an $\mathrm{X}$ - or $\mathrm{Y}$-type active end on a growing polymer as follows:

$$
\begin{array}{ll}
X-X-Y-X-Y-X^{*}: & X^{*} \\
X-Y-Y-X-Y-Y^{*}: & Y^{*} .
\end{array}
$$

Activation is thought to occur according to the following equations:

$$
\begin{aligned}
& \mathrm{X}+\mathrm{X} \rightarrow \mathrm{X}^{*} \\
& \mathrm{Y}+\mathrm{Y} \rightarrow \mathrm{Y}^{*} \\
& \mathrm{X}+\mathrm{Y} \rightarrow \mathrm{X}^{*} \text { or } \mathrm{Y}^{*} .
\end{aligned}
$$

Furthermore, a transfer of the activated point may also be considered in the following manner:

$$
\mathrm{X}^{*}+\mathrm{Y} \rightarrow \mathrm{X}+\mathrm{Y}^{*} \text {. }
$$

The next step is the growth or propagation of the activated molecules. We assume that the growth rate is determined only by 
the types or species of the terminal radical on the active polymer and by the monomer to be added. Therefore, the following four types of rate constants can be considered:

$$
\begin{aligned}
& \mathrm{X}^{*}+\mathrm{X} \rightarrow \mathrm{X}^{*}\left(k_{\mathrm{xx}}\right) \\
& \mathrm{X}^{*}+\mathrm{Y} \rightarrow \mathrm{Y}^{*}\left(k_{\mathrm{xy}}\right) \\
& \mathrm{Y}^{*}+\mathrm{X} \rightarrow \mathrm{X}^{*}\left(k_{\mathrm{yx}}\right) \\
& \mathrm{Y}^{*}+\mathrm{Y} \rightarrow \mathrm{Y}^{*}\left(k_{\mathrm{yy}}\right) .
\end{aligned}
$$

For the termination reaction, the analysis made for single polymerizations can be extended to mixed polymerizations. However, termination of mixed polymerization systems will not be considered in this paper because the degree of polymerization will not be discussed here.

Various representative forms of mixed polymerization reactions will be explained by applying the aforementioned mechanisms of activation and growth.

\section{VARIOUS FORMS OF MIXED POLYMERIZATION}

Mixed polymerization of monomers that are difficult to polymerize separately

It is reported that stilbene and maleic anhydride are difficult to polymerize independently, but polymerization proceeds easily when they are mixed, as explained by the following: The activation of $\mathrm{X}$ or $\mathrm{Y}$ occurs as

$$
\mathrm{X} \rightarrow \mathrm{X}^{*} \text {, or } \mathrm{Y} \rightarrow \mathrm{Y}^{*} .
$$

However, growth does not proceed because the reaction rates at which $\mathrm{X}$ and $\mathrm{Y}$ are added to $\mathrm{X}^{*}$ and $\mathrm{Y}^{*}$, respectively, are too low. Thus, single polymerizations of these monomers do not occur. In contrast, the rates at which $\mathrm{Y}$ is added to $\mathrm{X}^{*}$ and $\mathrm{X}$ is added to $\mathrm{Y}^{*}$ are relatively high, that is,

$$
k_{\mathrm{xy}} \gg k_{\mathrm{xx}}, k_{\mathrm{yx}} \gg k_{\mathrm{yy}} \text {. }
$$

As a result, mixed polymerization proceeds. If the reaction takes place in accordance with the aforementioned scheme, $\mathrm{Y}$ should be bonded to $\mathrm{X}$, and $\mathrm{X}$ should be bonded to $\mathrm{Y}$, resulting in the following structure:

$$
-\mathrm{X}-\mathrm{Y}-\mathrm{X}-\mathrm{Y}-\mathrm{X}-\mathrm{Y}-\mathrm{X}-\mathrm{Y}-\mathrm{X}-\mathrm{Y}-\mathrm{X}-\mathrm{Y}-.
$$

In fact, according to the studies of Wagner-Jauregg, the mixed polymerization of stilbene and maleic anhydride yields products of 1:1 composition, regardless of the feed monomer ratio.

Polymerization of a compound that is hardly polymerizable in the presence of an easily polymerizable compound

Dichloroethylene is difficult to polymerize; however, when it is mixed with a compound that is easily polymerizable, such as vinyl acetate, mixed polymerization occurs. Various mechanisms for this type of mixed polymerization can be considered. Here, the easily polymerizable compound is symbolized by $\mathrm{X}$, and the compound that is difficult to polymerize is symbolized by $\mathrm{Y}$. Activation occurs for $\mathrm{X}$ as $\mathrm{X} \rightarrow \mathrm{X}^{*}$. If activation of $\mathrm{Y} \rightarrow \mathrm{Y}^{*}$ does not occur at all, single polymerization of $\mathrm{Y}$ also does not take place. However, if $k_{\mathrm{xy}} \neq 0$, $\mathrm{Y}$ will be polymerized as well. In such cases, the reaction is terminated immediately after $\mathrm{Y}$ is added to $\mathrm{X}$ as long as conditions of both $k_{\mathrm{yy}} \neq 0$ and $k_{\mathrm{yx}} \neq 0$ do not exist. Furthermore, when the activation of $Y$ does not occur independently, Y may be activated via migration of the active site

$$
\mathrm{X}^{*}+\mathrm{Y} \rightarrow \mathrm{X}+\mathrm{Y}^{*}
$$

Once $\mathrm{Y}$ is activated, growth can occur.
The following text provides a second interpretation. Although the activation of $\mathrm{Y} \rightarrow \mathrm{Y}^{*}$ takes place, the growth of $\mathrm{Y}^{*}+\mathrm{Y} \rightarrow \mathrm{Y}^{*}$ does not occur because $k_{\mathrm{yy}}=0$. Therefore, single polymerization does not take place, whereas mixed polymerization occurs if both $k_{\mathrm{xy}} \neq 0$ and $k_{\mathrm{yx}} \neq 0$. According to this interpretation, adjacent $\mathrm{X}-\mathrm{X}$ bonds should be present in the resulting polymer, but adjacent $\mathrm{Y}-\mathrm{Y}$ bonds will not be observed. The $\mathrm{Y}$ content in the product should always be lower than that of $\mathrm{X}$. Thus, tests to determine the presence of two continuous Ys in the product should tell us which of the previously described mechanisms is correct.

In addition to the combination of vinyl acetate and dichloroethylene, mixed polymerizations of vinyl acetate and trichloroethylene and of styrene and maleic anhydride seem to follow this mechanism.

\section{Decrease in polymerizability of two easily polymerizable substances upon mixing}

Styrene and vinyl acetate are easily polymerized separately; however, when mixed, only styrene is polymerized unless vinyl acetate is added in an overwhelming excess. In the latter case, the activation of $\mathrm{X} \rightarrow \mathrm{X}^{*}$ and $\mathrm{Y} \rightarrow \mathrm{Y}^{*}$ certainly occurs, but the addition of $\mathrm{X}$ predominates over that of $\mathrm{Y}$ due to the reaction conditions,

$$
k_{\mathrm{xx}} \gg k_{\mathrm{xy}} \text { and } k_{\mathrm{yx}} \gg k_{\mathrm{yy}} \text {. }
$$

\section{Polymerization in which each component is independently} polymerized

In this case, each component is activated as $\mathrm{X} \rightarrow \mathrm{X}^{*}$ and $\mathrm{Y} \rightarrow \mathrm{Y}^{*}$, and the addition of $\mathrm{X}$ to $\mathrm{X}^{*}$ and of $\mathrm{Y}$ to $\mathrm{Y}^{*}$ proceeds at a considerable rate. However, because

$$
k_{\mathrm{xx}} \gg k_{\mathrm{xy}}, k_{\mathrm{yy}} \gg k_{\mathrm{yx}},
$$

the addition of $\mathrm{Y}$ to $\mathrm{X}^{*}$ and of $\mathrm{X}$ to $\mathrm{Y}^{*}$ rarely occurs, resulting only in single polymerization of each component even when $\mathrm{X}$ and $\mathrm{Y}$ are combined. Mixed polymerization of methacrylester and acrylonitrile is a prime example of this type of polymerization.

\section{Production of copolymers}

If any of the four rate constants for a growth reaction are non-zero and comparable in magnitude to one another, that is,

$$
k_{\mathrm{xx}} \neq 0, k_{\mathrm{xy}} \neq 0, k_{\mathrm{yy}} \neq 0, k_{\mathrm{yx}} \neq 0,
$$

a copolymer is produced. During this process, the composition changes as the polymerization proceeds. Inevitably, there are considerable differences in composition, properties and so on, of the products obtained during the initial and late stages of the polymerization. The copolymerization of vinyl acetate with acrylonitrile is an example of this type of reaction.

\section{Production of true (perfectly random) copolymers}

A copolymer having a composition ratio equal to the feed monomer ratio is called a true or perfectly random copolymer. [Editorial note: Both 'true coplolymer' and 'perfectly random copolymer' were termed by Wall.] Such a copolymer is produced under the following conditions:

$$
k_{\mathrm{xx}}=k_{\mathrm{xy}}, k_{\mathrm{yy}}=k_{\mathrm{yx}} .
$$

The reason for this will be explained in the following section. Examples of such systems may include vinyl chloride and vinyl acetate, 
methacrylic acid and methyl methacrylate, methyl methacrylate and its nitrile, and methacrylic acid and its nitrile.

\section{GENERAL TREATMENT OF MIXED POLYMERIZATION REACTIONS}

On the basis of equation (41), the polymerization rates of $\mathrm{X}$ and $\mathrm{Y}$ can be expressed as follows:

$$
\begin{aligned}
& -d[\mathrm{X}] / d t=k_{\mathrm{xx}}\left[\mathrm{X}^{*}\right][\mathrm{X}]+k_{\mathrm{yx}}\left[\mathrm{Y}^{*}\right][\mathrm{X}] \\
& -d[\mathrm{Y}] / d t=k_{\mathrm{xy}}\left[\mathrm{X}^{*}\right][\mathrm{Y}]+k_{\mathrm{yy}}\left[\mathrm{Y}^{*}\right][\mathrm{Y}] .
\end{aligned}
$$

The polymerization ratio of $\mathrm{X}$ and $\mathrm{Y}$ at each moment is given by

$$
d[\mathrm{X}] / d[\mathrm{Y}]=\left\{\left(k_{\mathrm{yx}}+k_{\mathrm{xx}}\left(\left[\mathrm{X}^{*}\right] /\left[\mathrm{Y}^{*}\right]\right)\right) /\left(k_{\mathrm{yy}}+k_{\mathrm{xy}}\left(\left[\mathrm{X}^{*}\right] /\left[\mathrm{Y}^{*}\right]\right)\right)\right\}([\mathrm{X}] /[\mathrm{Y}]) .
$$

Next, we consider the steady state in a mixed polymerization reaction in which neither an increase nor decrease in $\left[\mathrm{X}^{*}\right]$ and $\left[\mathrm{Y}^{*}\right]$ occurs at any given moment. In this state, the reactions related to the constants $k_{\mathrm{xx}}$ and $k_{\mathrm{yy}}$ in equation (41) can be neglected because they do not change the concentrations of $\mathrm{X}^{*}$ and $\mathrm{Y}^{*}$, respectively. In short, the steady state is established when an equilibrium forms between the production and disappearance of $\mathrm{X}^{*}$ (or the disappearance and production of $\mathrm{Y}^{*}$ ) caused by the constants $k_{\mathrm{yx}}$ and $k_{\mathrm{xy}}$, respectively, that is,

$$
k_{\mathrm{yx}}\left[\mathrm{Y}^{*}\right][\mathrm{X}]=k_{\mathrm{xy}}\left[\mathrm{X}^{*}\right][\mathrm{Y}] \text {. }
$$

The equation can be rewritten as follows:

$$
\left[\mathrm{X}^{*}\right] /\left[\mathrm{Y}^{*}\right]=\left(k_{\mathrm{yx}} / k_{\mathrm{xy}}\right)([\mathrm{X}] /[\mathrm{Y}]) .
$$

By substituting equation (44) into equation (43), we obtain

$$
d[\mathrm{X}] / d[\mathrm{Y}]=\{(1+(k \mathrm{xx} / k \mathrm{xy})([\mathrm{X}] /[\mathrm{Y}])) /(k \mathrm{yy} / k \mathrm{yx}+[\mathrm{X}] /[\mathrm{Y}])\}([\mathrm{X}] /[\mathrm{Y}]) .
$$

Under the conditions

$$
k_{\mathrm{xx}}=k_{\mathrm{xy}} ; k_{\mathrm{yx}}=k_{\mathrm{yy}},
$$

equation (45) becomes

$$
d[\mathrm{X}] / d[\mathrm{Y}]=[\mathrm{X}] /[\mathrm{Y}] .
$$

Thus, at any given moment, polymerization occurs in a ratio that is identical to the ratio of the monomer feed. Under these conditions, a true (perfectly random) copolymer is obtained. In other words, the production of true copolymers is controlled by the active site species in the growth reaction and is independent of the identity of the monomer added.

Reversing the above condition leads to a special alternative. We may assume that

$$
k_{\mathrm{xx}}=k_{\mathrm{yx}} \text { and } k_{\mathrm{xy}}=k_{\mathrm{yy}} \text {. }
$$

In this case, equation (45) transforms to

$$
d[\mathrm{X}] / d[\mathrm{Y}]=\left(k_{\mathrm{xx}} / k_{\mathrm{yy}}\right)([\mathrm{X}] /[\mathrm{Y}]),
$$

and true copolymers are not produced.

Next we consider the general case. The general equation without imposing any limitations on the rate constants can be written as follows:

$$
d[\mathrm{X}] / d[\mathrm{Y}]=\alpha([\mathrm{X}] /[\mathrm{Y}]) .
$$

Substituting equation (47) into equation (45) and applying a deformation, we obtain

$$
[\mathrm{X}] /[\mathrm{Y}]-1 / \alpha=\left(k_{\mathrm{xx}} / k_{\mathrm{xy}}\right)(1 / \alpha)([\mathrm{X}] /[\mathrm{Y}])-k_{\mathrm{yy}} / k_{\mathrm{yx}} .
$$

Let us suppose that a mixed polymerization reaction is initiated at a predetermined mixing ratio of $\mathrm{X}$ and $\mathrm{Y}$ and that the polymer produced is isolated and quantified at each time interval to determine its instantaneous composition. A curve showing the relationship between $[\mathrm{X}]$ and $[\mathrm{Y}]$ can be calculated. The tangent at any point on the curve gives $d[\mathrm{X}] / d[\mathrm{Y}]$. Thus, $\alpha$ can easily be determined experimentally. [Editorial note: equation (48) also applies to copolymers that are instantaneously produced starting with differing feed-monomer ratios. (I Sakrada, M Yoshida, Kobunshi Kagaku, 7, 334 (1950)). In fact, this equation is equivalent to the so-called Fineman-Ross plot. (M Fineman, SD Ross, J. Polymer Sci., 5, 269 (1950)) (see the Foreword)].

Once the value of $\alpha$ is obtained, we can draw a curve for the relationship between $[\mathrm{X}] /[\mathrm{Y}]-1 / \alpha$ and $(1 / \alpha)([\mathrm{X}] /[\mathrm{Y}])$ using equation (48). If the theory developed herein is correct, the curve should be a straight line; the slope of the line yields $k_{\mathrm{xx}} / k_{\mathrm{xy}}$, and its intercept with the axis, $[\mathrm{X}] /[\mathrm{Y}]-1 / \alpha$, gives $k_{\mathrm{yy}} / k_{\mathrm{yx}}$.

The experimental results of the mixed polymerization of acrylonitrile and vinyl acetate, obtained by Okamura, Ota and other members of our laboratory are in good agreement with the proposed theory. A detailed analysis will be reported in the future. According to the proposed method, the following results were obtained:

$$
k_{\mathrm{xx}} / k_{\mathrm{xy}}=3.2, k_{\mathrm{yy}} / k_{\mathrm{yx}}=0 ; \text { or } k_{\mathrm{yy}} \ll k_{\mathrm{yx}}
$$

for which $\mathrm{X}$ and $\mathrm{Y}$ are acrylonitrile and vinyl acetate, respectively. When $\mathrm{X}$ and $\mathrm{Y}$ are replaced with $\mathrm{N}$ (for nitrile) and $\mathrm{A}$ (for acetate), respectively, the above results show that bonds of $-\mathrm{A}-\mathrm{A}-$ are hardly produced; $\mathrm{N}$ is bonded overwhelmingly to A to yield $\mathrm{A}-\mathrm{N}$ bonds; and $-\mathrm{N}-\mathrm{N}-$ bonds are produced approximately three times more often than $-\mathrm{N}-\mathrm{A}-$ bonds under the same conditions.

Using the procedure described above, various mixed polymerization reactions could also be analyzed.

Under the title of 'High Polymerization Reaction', I have thus far reviewed addition polymerization reactions and discussed in detail those matters of particular interest to us that are currently being studied in our laboratory. 